\title{
The future of psychotherapy research: stop the waste and focus on issues that matter
}

\author{
P. Cuijpers ${ }^{1,2}$ \\ ${ }^{1}$ Department of Clinical, Neuro and Developmental Psychology, VU University Amsterdam, Amsterdam, The Netherlands \\ ${ }^{2}$ EMGO Institute for Health and Care Research, Amsterdam, The Netherlands
}

First published online 9 September 2015

Key words: Antidepressants, behaviour therapy, cognitive therapy, depression, psychotherapy.

It is well-established that psychotherapies can effectively treat depression. In the past four decades, more than 400 randomized controlled trials have been conducted (Cuijpers, 2015), showing that different types of psychotherapy are effective (Barth et al. 2013), that the effects do not or only marginally differ from each other, that they are comparable with those of antidepressants, and that combined treatment is more effective than psychotherapy or medication alone (Cuijpers, 2014). However, psychotherapies are probably less effective in chronic depression and dysthymia, when patients have comorbid alcohol problems, and in subthreshold depression, although in these patients therapies can prevent the onset of full-blown major depressive disorders (Cuijpers et al. 2014).

The two Editorials in this issue give interesting perspectives on where we are with research on these therapies and what should happen in the future (Hollon, 2015; Solomonov \& Barber, 2015). The first thing that stands out is that both agree that although psychotherapies are effective, there is still considerable room for improvement. The Editorials point at the problem that the effects of psychotherapy have been overestimated because of publication bias, but also that the longer term effects of psychotherapies are not well known, except maybe for cognitive-behavioural therapy where longer-term effects have been shown (Karyotaki et al. 2014) in several trials. The small effects of psychotherapies and treatments in general in chronic and treatment-resistant depression (Cuijpers et al. 2010d) and the high relapse rates after successful recovery (Vittengl et al. 2007) are also important problems.

I want to underscore that although therapies are effective, there is still much room for improvement.

\footnotetext{
Address for correspondence: Professor P. Cuijpers, Department of Clinical Psychology, VU University Amsterdam, Van der Boechorststraat 1, 1081 BT Amsterdam, The Netherlands.

(Email: p.cuijpers@vu.nl)
}

The effect sizes found for treatments for mental disorders do not differ very much from those in general medical disorders (Leucht et al. 2012), but still it is estimated that current treatments cannot take away more than one-third of the disease burden of depression, and then only in optimal conditions (Andrews et al. 2004). And then there is the problem that more than $40 \%$ of the patients do not or only partially respond to treatment and less than one-third of the patients are completely recovered after treatment (Hollon et al. 2002). And after successful response the relapse rates are estimated to be $50 \%$ after 2 years and up to $80 \%$ after 5 years (Vittengl et al. 2007). These problems are in addition to the problem that much of the earlier research has considerably overestimated the effects of acute treatments of depression, not only because of publication bias, but also because of the low quality of many trials in the field (Cuijpers et al. 2010c) and probably researcher allegiance (Munder et al. 2013).

Both articles give indications for how future research can contribute to a further reduction of the disease burden. In addition to that, however, I would like to stress that there is also much research that is not needed anymore in the future. In the broader biomedical field it is estimated that about $85 \%$ of research is wasted, because of irrelevant questions, inappropriate designs and methods, and biased reporting (Chalmers \& Glasziou, 2009). There is no reason to assume that this is very different in randomised trials of psychotherapies for depression. We found earlier that of 115 trials in this field only 11 met all nine generally accepted quality criteria, and that the effects of these 11 studies were considerably smaller than those of lower-quality studies (Cuijpers et al. 2010c). We also found that adjusting for unpublished trials reduces the effect size of psychotherapies with more than one-third (Cuijpers et al. 2010b), and reporting in these trials also is often biased (Flint et al. 2014). 
In addition to that, a considerable number of studies report on the effects of newly developed psychotherapies for depression (e.g., Bédard et al. 2014; Giosan et al. 2014) and on comparative trials comparing two types of psychotherapies. It is well-established, however, that all therapies for depression are about equally effective (Barth et al. 2013) and that if a new therapy would indeed be more effective than an existing therapy, it would take a new trial with about 800 patients to show its superiority (Cuijpers \& van Straten, 2011). If a therapy is found to be superior to an existing therapy in an underpowered trial that would rather raise doubts about the validity of the trial than trust that this new therapy is indeed more effective.

Other trials have focused on examining psychotherapies for depression in specific target populations, like older adults, women with postpartum depression and patients with comorbid general medical disorders. However, meta-analyses consistently show that psychotherapies are effective in all such target groups (Cuijpers et al. 2008). By far the majority of trials examining psychotherapies for depression find positive effects, whether these are in specific target groups or in unselected populations of adults. It seems therefore not necessary to spend resources on examining these therapies in all such specific target groups.

In the same way it can be argued that it is no longer needed to examine different treatment formats in randomised controlled, because all research consistently suggests that individual, group, guided self-help and guided Internet-based therapies formats result in comparable outcomes (Cuijpers et al. 2010a; Andersson et al. 2014).

In order to reduce the disease burden of depression much research is needed in many areas. The two articles give several directions for future directions in research on psychological treatments, including research how to reduce drop-out rates for psychotherapies, because they use considerable resources with apparently little benefits (Solomonov \& Barber, 2015). But also more research on the long-term effects of therapies, treatment-resistant and chronic depression, the high relapse rates and more knowledge on who benefits from which treatment are important goals for future research, as justly indicated in these two articles in this issue.

In this context it could be added that it is also important to examine how treatments work, because if we understand the processes of how therapies work we may finally start improving the effects of therapies. However, examining working mechanisms of treatments is notoriously complicated (Kazdin, 2007), and requires different types of research, including not only research on mediators in randomised trials, but also experimental studies, theoretical work and animal studies. Although this will require quite some resources, it will be one of the few ways how we can improve the effects of treatments. It has been shown that all pharmacological therapies are about equally effective, that all psychological treatments are equally effective, and that pharmacological and psychological treatments are also equally effective. That means that all treatments we have are about equally effective, while we hardly know anything about who benefits from which treatment. This basically implies that the effects of treatments have not been improved since the 1950s when the tricyclic antidepressants (TCAs) were first tested.

The other approach to a further reduction of the disease burden of depression is to focus on improvement of how to apply treatments better in routine care and how to scale treatment up. Although the effects of treatments may not have improved since their first development, mental health care has made considerable progress in terms of reaching depressed patients and applying therapies to people who can benefit from therapies. That is important because large group of patients who may benefit from treatment still do not use these services enough, like adolescents, older adults, minority and lower socioeconomic groups. And in low- and middle income countries treatments are hardly available at all. It is important therefore to simplify therapies and make them more accessible.

The suggestion by Solomonov and Barber to develop stepwise treatment models offers therefore an interesting perspective, with the simplest and cheapest treatments first, followed by more complicated and intensive therapies. That is in line with more generic models that are aimed at improving existing treatments and making them more efficient, like stepped care (van Straten et al. 2015) and collaborative care models (Coventry et al. 2014). But there are also other ways to improve access and simplify treatments without reducing their effects, like using trained lay health counsellors for the delivery of treatments in low-resourced countries, as has been done in India (Patel et al. 2010), or using Internet-based guided selfhelp therapies which cost much less time than traditional, individual therapies (Andersson \& Cuijpers, 2009).

Psychotherapies and other treatments for adult depression are effective, but there is also much room for improvement. The two Editorials in this issue give a nice overview of where we are and where we should be heading. We need much research, on the long-term effects, on treatments of chronic and treatment-resistant depression, on relapse, and on working mechanisms. But there is also much research 
which we no longer need because it has been examined sufficiently, like new therapies that promise superior effects over existing therapies while they always show equal effects. Resources are scarce and using them for unnecessary research will slow down progress and let patients with depression suffer more than needed.

\section{Acknowledgement}

None.

\section{Financial Support}

This research received no specific grant from any funding agency, commercial or not-for-profit sectors.

\section{Conflict of Interest}

None.

\section{References}

Andersson G, Cuijpers P (2009). Internet-based and other computerized psychological treatments for adult depression: a meta-analysis. Cognitive Behaviour Therapy 38, 196-205.

Andersson G, Cuijpers P, Carlbring P, Riper H, Hedman E (2014). Guided Internet-based vs. face-to-face cognitive behavior therapy for psychiatric and somatic disorders: a systematic review and meta-analysis. World Psychiatry: Official Journal of the World Psychiatric Association (WPA) 13, 288-295.

Andrews G, Issakidis C, Sanderson K, Corry J, Lapsley H (2004). Utilising survey data to inform public policy: comparison of the cost-effectiveness of treatment of ten mental disorders. The British Journal of Psychiatry: The Journal of Mental Science 184, 526-533.

Barth J, Munder T, Gerger H, Nüesch E, Trelle S, Znoj H, Jüni P, Cuijpers P (2013). Comparative efficacy of seven psychotherapeutic interventions for patients with depression: a network meta-analysis. PLoS Medicine 10, e1001454.

Bédard M, Felteau M, Marshall S, Cullen N, Gibbons C, Dubois S, Maxwell H, Mazmanian D, Weaver B, Rees L, Gainer R, Klein R, Moustgaard A (2014).

Mindfulness-based cognitive therapy reduces symptoms of depression in people with a traumatic brain injury: results from a randomized controlled trial. The Journal of Head Trauma Rehabilitation 29, E13-E22.

Chalmers I, Glasziou P (2009). Avoidable waste in the production and reporting of research evidence. Lancet (London, England) 374, 86-89.

Coventry PA, Hudson JL, Kontopantelis E, Archer J, Richards DA, Gilbody S, Lovell K, Dickens C, Gask L, Waheed W, Bower P (2014). Characteristics of effective collaborative care for treatment of depression: a systematic review and meta-regression of 74 randomised controlled trials. PLOS ONE 9, e108114.
Cuijpers P (2014). Combined pharmacotherapy and psychotherapy in the treatment of mild to moderate major depression? JAMA Psychiatry 71, 747-748.

Cuijpers P (2015). Psychotherapies for adult depression: recent developments. Current Opinion in Psychiatry 28, 24-29.

Cuijpers P, van Straten A (2011). New psychotherapies for mood and anxiety disorders: necessary innovation or waste of resources? Canadian Journal of Psychiatry. Revue Canadienne De Psychiatrie 56, 251; author reply 251-252.

Cuijpers P, Van Straten A, Warmerdam L, Smits N (2008). Characteristics of effective psychological treatments of depression: a metaregression analysis. Psychotherapy Research: Journal of the Society for Psychotherapy Research 18, 225-236.

Cuijpers P, Donker T, van Straten A, Li J, Andersson G (2010a). Is guided self-help as effective as face-to-face psychotherapy for depression and anxiety disorders? A systematic review and meta-analysis of comparative outcome studies. Psychological Medicine 40, 1943-1957.

Cuijpers P, Smit F, Bohlmeijer E, Hollon SD, Andersson G (2010b). Efficacy of cognitive-behavioural therapy and other psychological treatments for adult depression: meta-analytic study of publication bias. The British Journal of Psychiatry: The Journal of Mental Science 196, 173-178.

Cuijpers P, van Straten A, Bohlmeijer E, Hollon SD, Andersson G (2010c). The effects of psychotherapy for adult depression are overestimated: a meta-analysis of study quality and effect size. Psychological Medicine 40, 211-223.

Cuijpers P, van Straten A, Schuurmans J, van Oppen P, Hollon SD, Andersson G (2010d). Psychotherapy for chronic major depression and dysthymia: a meta-analysis. Clinical Psychology Review 30, 51-62.

Cuijpers P, Koole SL, van Dijke A, Roca M, Li J, Reynolds CF (2014). Psychotherapy for subclinical depression: meta-analysis. The British Journal of Psychiatry: The Journal of Mental Science 205, 268-274.

Flint J, Cuijpers P, Horder J, Koole SL, Munafò MR (2014). Is there an excess of significant findings in published studies of psychotherapy for depression? Psychological Medicine, 1-8.

Giosan C, Cobeanu O, Mogoase C, Muresan V, Malta LS, Wyka K, Szentagotai A (2014). Evolutionary cognitive therapy versus standard cognitive therapy for depression: a protocol for a blinded, randomized, superiority clinical trial. Trials 15, 83.

Hollon SD (2015). The efficacy and acceptability of psychological interventions for depression: where we are now and where we are going. Epidemiology and Psychiatric Sciences. doi:10.1017/S2045796015000748.

Hollon SD, Muñoz RF, Barlow DH, Beardslee WR, Bell CC, Bernal G, Clarke GN, Franciosi LP, Kazdin AE, Kohn L, Linehan MM, Markowitz JC, Miklowitz DJ, Persons JB, Niederehe G, Sommers D (2002). Psychosocial intervention development for the prevention and treatment of depression: promoting innovation and increasing access. Biological Psychiatry 52, 610-630.

Karyotaki E, Smit Y, Cuijpers P, Debauche M, De Keyser T, Habraken H, Pitchot W, Raes F, Salomez D, Gillain B, 
Fairon N, Paulus D, Robays J, Holdt Henningsen K (2014). The Long-Term Efficacy of Psychotherapy, Alone or in Combination with Antidepressants, in the Treatment of Adult Major Depression. KCE, Federaal Kenniscentrum voor de Gezondheidszorg: Brussels.

Kazdin AE (2007). Mediators and mechanisms of change in psychotherapy research. Annual Review of Clinical Psychology 3, 1-27.

Leucht S, Hierl S, Kissling W, Dold M, Davis JM (2012). Putting the efficacy of psychiatric and general medicine medication into perspective: review of meta-analyses. The British Journal of Psychiatry: The Journal of Mental Science 200, 97-106.

Munder T, Brütsch O, Leonhart R, Gerger H, Barth J (2013). Researcher allegiance in psychotherapy outcome research: an overview of reviews. Clinical Psychology Review 33, 501-511.

Patel V, Weiss HA, Chowdhary N, Naik S, Pednekar S, Chatterjee S, De Silva MJ, Bhat B, Araya R, King M,
Simon G, Verdeli H, Kirkwood BR (2010). Effectiveness of an intervention led by lay health counsellors for depressive and anxiety disorders in primary care in Goa, India (MANAS): a cluster randomised controlled trial. Lancet (London, England) 376, 2086-2095.

Solomonov N, Barber JP (2015). What we know, what we do not know, and where are we heading? Efficacy and acceptability of psychological interventions for depression. Epidemiology and Psychiatric Sciences. doi:10.1017/ S2045796015000815.

van Straten A, Hill J, Richards DA, Cuijpers P (2015). Stepped care treatment delivery for depression: a systematic review and meta-analysis. Psychological Medicine 45, 231-246.

Vittengl JR, Clark LA, Dunn TW, Jarrett RB (2007). Reducing relapse and recurrence in unipolar depression: a comparative meta-analysis of cognitive-behavioral therapy's effects. Journal of Consulting and Clinical Psychology 75, 475-488. 